\title{
IMPARCIALIDADE E OBRIGAÇÃO NA FILOSOFIA MORAL DE PETER SINGER
}

\section{IMPARTIALITY AND OBLIGATION IN THE MORAL PHILOSOPHY OF PETER SINGER}

\author{
Anselmo Carvalho de Oliveira ${ }^{1}$
}

Recebido: 03/2019

Aprovado: 10/2019

\begin{abstract}
Resumo: O artigo discute a ideia de imparcialidade na filosofia moral de Peter Singer. (1) Primeiro, apresenta, em linhas gerais, a ideia de imparcialidade para o filósofo australiano. (2) Depois, discutem-se as implicações da imparcialidade na tese sobre as obrigações dos ricos em ajudar os pobres. (3) Em seguida, discute-se a distinção entre obrigatório e super-rogatório e, a partir dessa distinção, constrói-se uma crítica à exigência de imparcialidade por parte do agente. (4) Discute-se a crítica de que a imparcialidade desconsideraria o altruísmo autorreferente como um aspecto central e irrenunciável da vida das pessoas. (5) Por fim, apresentam-se os argumentos utilizados por Singer para responder às críticas à imparcialidade: (5.1) o apelo à ideia cristã do dízimo; (5.2) a ideia de nível intuitivo do pensamento moral; (5.3) a justificativa imparcial da parcialidade.
\end{abstract}

Palavras-chave: Imparcialidade, Obrigatório, Super-rogatório, Ética da Fantasia, Peter Singer.

\begin{abstract}
This article discusses the idea of impartiality in moral philosophy. (1) First, it outlines the idea of impartiality in Singer's moral philosophy. (2) The implications of impartiality in the thesis on the obligations of the rich to help the poor are discussed. (3) Next, the distinction between mandatory and supererogatory is discussed and, from this distinction, a criticism is proposed of the agent's requirement of impartiality. (4) The criticism that impartiality would disregard selfreferential altruism as a central and inalienable aspect of people's lives is analyzed. (5) Finally, we present the arguments used by Singer to respond to criticisms of impartiality: (5.1) the appeal to the Christian idea of tithe; (5.2) the idea of an intuitive level of moral thought; (5.3) the impartial justification of partiality.
\end{abstract}

Key-words: Impartiality, Mandatory, Supererogatory, Ethics of Fantasy, Peter Singer.

\section{Introdução}

Na filosofia moral contemporânea, o debate sobre a imparcialidade ocupa um lugar central. Esse debate envolve questões de metaética (se o ponto de vista da ética deve ser

\footnotetext{
${ }^{1}$ Programa de Pós-Graduação em Economia Aplicada (PPEA) da Universidade Federal de Ouro Preto (UFOP). Email: anselmocarvalhooliveira@yahoo.com.br Lattes: http://buscatextual.cnpq.br/buscatextual/visualizacv.do?id=K4711643D6. ORCID: http://orcid.org/00000002-6967-9782. Google Acadêmico: https://scholar.google.com.br/citations?user=1-co0UsAAAAJ\&hl=pt-BR
} 
imparcial) e questões de ética normativa (se um princípio moral substancial deve levar à igual consideração de cada um). Teorias que propõem o véu de ignorância ou a universalizabilidade reivindicam a imparcialidade como tese fundamental. A imparcialidade substancial é central no consequencialismo, no utilitarismo, na ética dos direitos e na deontologia de inspiração kantiana. No contexto dessas teorias, os princípios e obrigações morais e os projetos de cada indivíduo são legitimados em referência ao requisito da imparcialidade (BLUM, 1986, p. 344).

Os objetivos do texto foram discutir a tese da imparcialidade a partir da perspectiva do utilitarismo de preferências proposto por Peter Singer, apresentar duas críticas recebidas por teorias estritamente imparciais, bem como as possíveis respostas para essas críticas a partir do arcabouço teórico desenvolvido pelo filósofo australiano.

O texto estrutura-se em cinco seções, além dessa introdução e das considerações finais. Na próxima seção, discutiu-se a ideia de imparcialidade restrita. $\mathrm{Na}$ seção seguinte, foram apresentados os argumentos de Singer para apoiar a tese da obrigação de ajudar. Na seção quatro, foram apresentadas as distinções entre super-rogatório e obrigatório. Na seção cinco, foi discutida a tese da imparcialidade do utilitarismo ao levar à ética da fantasia. E, por fim, na seção cinco, foram apresentados argumentos construídos com o arcabouço teórico do utilitarismo de preferência de Singer para responder às críticas à imparcialidade na teoria moral.

\section{Imparcialidade restrita}

Princípios e juízos morais são concebidos no utilitarismo a partir de um ponto de vista estritamente imparcial. A imparcialidade implica que, do ponto de vista da ética, o agente deve considerar os interesses de todos os afetados na sua decisão. Exige-se que não seja dado peso especial: 1) aos interesses, desejos e demandas subjetivas do agente; 2) tampouco que seja dado prioridade às demandas dos seus familiares, ou dos membros do seu círculo de relacionamento pessoal mais próximo; ou 3) do grupo ao qual pertence.

Para Gruen (1999, p. 130), a universalizabilidade avalizaria a imparcialidade, porque excluiria os princípios que favorecessem ou privilegiassem, pela sua própria formulação, perspectivas particulares. A imparcialidade, nesse sentido, não define quais são os conteúdos substanciais das prescrições a serem adotadas como guias para a ação e não é capaz de determinar se um princípio é justo ou injusto, mas seria capaz de determinar se um princípio é irracional ou racional. Para Gruen, é esse o tipo de imparcialidade no consequencialismo de Singer. 
Para Cottingham (1983, p. 84), a universalizabilidade não avalizaria a imparcialidade, mas exigiria que os princípios morais valham para todos os indivíduos que satisfaçam as suas especificações. Essa seria uma exigência de coerência lógica que os sistemas morais ou mesmo qualquer outro sistema de regras deveria respeitar. A diferença entre a tese da universalizabilidade e da imparcialidade ficaria clara no caso dos princípios egoístas. Esses princípios não seriam todos descartados pela universalizabilidade ${ }^{2}$. A imparcialidade seria capaz de rejeitar princípios que priorizassem o interesse do agente; por outro lado, a universalizabilidade não seria capaz de fazer o mesmo. O problema da universalizabilidade seria que ela não implica um tipo de imparcialidade capaz de determinar princípios substanciais e regras de conduta.

Gruen parece estar se referindo à imparcialidade no sentido de irrelevância numérica requisito formal exigido de uma teoria ética. A "imparcialidade formal”, ou de segunda ordem, não depende da teoria normativa. Cottingham parece atribuir à imparcialidade conteúdo substancial capaz de eliminar o egoísmo normativo e o altruísmo autorreferente. A “imparcialidade substancial”, por sua vez, depende da teoria normativa subjacente e do significado dos princípios substanciais de uma teoria. Por exemplo, a igualdade e a justiça podem ser consideradas de formas diferentes quando integradas como princípios de teorias normativas distintas, como no utilitarismo ou no contratualismo. Os princípios substanciais requerem uma justificativa normativa a partir do conteúdo da teoria moral especificada. A imparcialidade, no nível substancial, seria concebida por Singer consoante a uma abordagem utilitarista.

Singer rejeita explicitamente essa distinção entre imparcialidade formal avalizada pela universalizabilidade e imparcialidade substancial vinculada ao utilitarismo. A universalizabilidade é um requisito formal cuja correta aplicação seria capaz de avalizar pelo menos um princípio substancial: o de igual consideração de interesses (SINGER, 1999, p. 298; EP, p. 30).

\footnotetext{
2 "É um erro supor, como parece [fazer] Singer, que a exigência de que os juízos éticos sejam universalizáveis leva-nos, sem mais, a tese da imparcialidade. É verdade que os princípios morais devem valer também para todos aqueles que satisfazem todas as especificações constantes desses princípios. Mas isso não é mais do que um princípio de coerência - uma exigência puramente lógica para qualquer sistema moral ou mesmo qualquer outro sistema de regras que se devem respeitar. Não há nada nesta exigência lógica para determinar o conteúdo de nossos princípios morais: princípios egoístas (por exemplo, que cada pessoa deve se esforçar exclusivamente para promover seus próprios interesses) não são de todo descartados por esse tipo de universalizabilidade" (COTTINGHAM, 1983, p. 84). Essa mesma crítica é aplicável à imparcialidade formal explicitada por Gruen: ao aceitar, por exemplo, agir de forma egoísta em relação aos outros, aceito também que eles ajam de forma egoísta em relação a mim. Da mesma forma, atuo segundo um princípio que afirma que todos devem privilegiar os seus familiares (OGIEN, 2003, v.1, p. 790).
} 
A imparcialidade é associada por Singer (EP, p. 19) à máxima cristã "amar a teu próximo como a ti mesmo"3. A imparcialidade e a máxima cristã apresentariam exigências muito parecidas aos agentes que consentirem com elas. A máxima cristã exigiria que em todas as deliberações que eu fizer devo atribuir aos interesses do meu próximo (familiar, amigo, vizinho etc.) o mesmo peso atribuído aos meus próprios interesses. Se eu amo o próximo como a mim mesmo, então realizar aquilo que para ele é importante deve ter igual "força" sobre as capacidades que tenho de realizar o que é importante. Assim, não posso gastar meus recursos (tempo, dinheiro etc.), ainda que limitados, para melhorar meu bem-estar ou minhas oportunidades para o futuro. Por exemplo, estudar matemática causa-me uma grande satisfação, mas, antes que possa fazê-lo, devo considerar se não existe outra ação que maximize a utilidade no qual eu possa empregar meu tempo. Se aliviar a fome diminuir mais o sofrimento do que meus estudos, então, do ponto de vista de uma ética estritamente imparcial, estaria obrigado a abandonar os estudos para dedicar-me a aliviar a fome. A imparcialidade não permite que "planos e projetos que estão diretamente envolvidos com a minha própria felicidade" sejam considerados especiais (COTTINGHAM, 1983, p. 88). Tampouco se pode atribuir qualquer peso especial aos interesses e desejos das pessoas com as quais mantenho algum tipo de relação especial, como a família, os amigos, os companheiros de trabalho, entre outras (MACKIE, 2000, p. 149).

Uma das defesas mais famosas da concepção imparcial em ética explicita essa implicação. William Godwin, em sua obra Enquiry concerning political justice and its influence on moral and happiness, publicada em 1793, defende um modelo para a justiça imparcial. O livro possui tendência utilitarista: a justiça consiste em atuar de forma que a ação produza o maior benefício possível a partir de um ponto de vista imparcial.

Para Godwin, ninguém possui valor intrínseco maior do que outra pessoa, entretanto, podem existir razões objetivas que, do ponto de vista estritamente imparcial, justifiquem a atribuição de valor maior a determinadas pessoas em algumas circunstâncias. Os interesses de todos os envolvidos têm que ser pesados a partir de razões neutras a respeito do agente, ou grupos particulares, isto é, razões imparciais. Não se pode dar-lhes uma consideração especial,

\footnotetext{
${ }^{3}$ A associação entre a máxima cristã e a tese da universalidade é feita, também, por outros autores utilitaristas. Segundo Stuart Mill (1995, p. 58, § II.18.5), "Na regra de ouro de Jesus de Nazaré, lemos todo o espirito da ética da utilidade. Tratar os outros como queremos que nos tratem e amar o nosso próximo como a nós mesmos constituem a perfeição ideal da moralidade utilitarista”. Hare (1965, p. 106, § 6.7), um importante utilitarista século $\mathrm{XX}$, estabelece o seu argumento da universalizabilidade para o utilitarismo como um tipo qualificado de argumento da Regra de Ouro: "Se ele fez isso, [adota princípios que desconsideram os interesses dos outros] ele se colocaria de fora do que iremos chamar de argumentos 'Regra de Ouro' ou 'utilitaristas', tornando-se o que chamaremos de fanático."
} 
porque são os interesses do теи grupo, do теи pai, ou о теи interesse.

Singer retoma algumas ideias centrais de Godwin: a) em situação extrema na qual se precisa escolher entre a vida de dois indivíduos, a escolha precisa ser justificada por razões utilitaristas ${ }^{4}$; b) a imparcialidade estrita exclui, a princípio, características relacionais como moralmente relevantes, ser filho de, mãe de, pai de, irmão de etc. Ser mãe de, por exemplo, é uma característica que não tem relação relevante com os "interesses moralmente significativos" como evitar a dor.

A teoria proposta por Singer leva ao que Cottingham (1983, p. 90) chama de "globalismo ético". Como os interesses de cada pessoa no planeta contam como um, a comunidade de consideração moral não pode identificar-se com os limites espaciais ou culturais que determinam um povo, uma comunidade, uma sociedade. Determinada sociedade precisa de normas de existência social, mas a ética não está limitada ao grupo com as suas leis específicas e a sua configuração territorial própria ${ }^{5}$. A imparcialidade, nessa concepção, não pode ser restrita a uma comunidade, povo, nação, país, Estado etc. Distâncias físicas e geográficas também não são moralmente relevantes. A consideração imparcial não permite discriminar alguém pela distância que ela se encontra do agente moral ${ }^{6}$. A imparcialidade no utilitarismo de preferências de Singer exige ainda mais: não são somente os interesses de todos os seres humanos que devem ser considerados imparcialmente, mas os de todos os indivíduos capazes de sofrer e que, por essa razão, têm interesses.

\footnotetext{
${ }^{4}$ É importante notar que o critério utilitarista de escolha somente deve ser aplicado em situações nas quais seja imprescindível fazer tal escolha. Para as decisões que não levam a escolhas em situações extremas cujas consequências prejudicam pelo menos um dos afetados, Singer não propõe que se façam cálculos utilitaristas, como veremos com mais cuidado à frente.

5 "O problema, porém, não é o que normalmente fazemos, mas o que deveríamos fazer, e é difícil encontrar qualquer justificativa moral bem-fundada para a concepção de que a distância, ou o fato de se pertencer a uma comunidade, tenha uma diferença crucial no que diz respeito às nossas obrigações" (Singer, EP, p. 243-244). "Do ponto de vista de uma sociedade particular, é essencial prevenir as violações das normas contra o assassinato, o roubo e coisas parecidas. Sem dúvida, não é de modo algum essencial ajudar as pessoas que se encontram fora de nossa própria sociedade. [...] A atitude moral nos exige olhar mais além dos interesses de nossa própria sociedade" (Singer, 2003j, p. 197).

${ }^{6}$ Uma exceção poderia ser os raros casos em que, por razões de logística, ajudar quem está mais próximo aumentará significativamente o bem-estar geral. Essa, no entanto, é uma razão que justificaria ajudar quem está próximo porque produz melhores consequências, mas não porque pertencem a um mesmo grupo ou possuem relações especiais que não são relevantes nas circunstâncias especificadas. É provável ou mais fácil que consideremos quem está mais próximo, isso é, uma questão de fato; mas a proximidade não pode ser tomada como um critério moral para determinar o que devemos fazer. Antigamente, a dificuldade de transporte e de comunicação em longas distâncias poderia ser uma razão para ajudar os que estavam próximos, mas, com a transformação do mundo em uma "aldeia global", os meios tecnológicos permitem ajudar quem está distante de forma "quase" tão eficaz quanto a nossa capacidade de ajudar ao próximo. Na concepção de Singer (2003j, p. 192), o fato de uma pessoa estar fisicamente próxima em relação ao agente moral e que, por isso, haja contato pessoal entre eles pode fazer com que seja mais provável a ajuda. Esse não é, entretanto, um argumento capaz de mostrar que devemos ajudar as pessoas próximas mais do que as que se encontram distantes. Assim, para Singer, parece não haver nenhuma justificativa moral para a discriminação por razões de proximidade ou geográficas.
} 
Existe um limite a partir do qual o agente não teria mais o dever de negligenciar as suas relações afetivas e os seus interesses próprios para diminuir o sofrimento dos outros?

\section{A obrigação de ajudar}

Para Singer, os ricos têm a obrigação moral de ajudar os mais pobres. A reivindicação não é que as pessoas ricas deveriam fazer uma contribuição que poderia salvar vidas nos países muito pobres, pois essa é uma ação altruísta e admirável de sua parte. A reinvindicação é mais forte: o agente deve distribuir todos os seus ganhos utilizando o critério segundo o qual os seus interesses ou da sua família e amigos não têm nenhum peso especial.

A obrigação imparcial de ajudar exige que se nem todos são comprometidos a ajudar ou, se a ajuda necessária for grande, então eu devo ajudar tanto quanto me for possível, ou seja, até o ponto a partir do qual ajudar mais causaria sérios danos a mim e aos que dependem de mim. Ajudar aos outros, na realidade, exigiria que chegássemos até o ponto a partir do qual, se continuássemos ajudando, causaríamos tanto sofrimento a nós mesmos e aos nossos dependentes quanto o sofrimento de quem estamos ajudando: “[...] é descer ao nível a partir do qual dar mais me causaria, a mim e aos que dependem de mim, mais sofrimento do que evitaria meu donativo" (SINGER, 2003j, p. 201) ${ }^{7}$.

A obrigação imparcial de ajudar impõe mudanças nos padrões ordinários do comportamento moral e, para minimizar os impactos dessas mudanças, Singer qualifica-a,

\footnotetext{
${ }^{7}$ Singer argumenta que se todos ajudarem até o limite da utilidade marginal pode haver mais do que o necessário, o que acabaria sendo um sacrifício desnecessário. Portanto, para alcançar o resultado, a saber, eliminar o sofrimento causado pela fome e pela falta de assistência médica, todos poderiam fazer um pouco menos do que são obrigados, pois o resultado dessa ação não seria "tão bom" quanto se todos fizessem o que deveriam ou somente alguns fizerem tudo o que deveriam fazer. Esse paradoxo depende de uma situação prática irreal, na qual todas as pessoas resolveriam cumprir a sua obrigação ao mesmo tempo. Para Singer, ao conhecer apropriadamente as circunstâncias e as reais condições para atingir os fins almejados no caso específico, o paradoxo se dissolveria: "O resultado de que todo o mundo faça o que realmente deveria fazer não pode ser pior que o resultado de que cada um faça menos do que deve, se bem que poderia sê-lo o resultado de cada um fizesse o que razoavelmente acredita que deveria fazer." (Singer, 2003j, p.195). Mas, nas circunstâncias nas quais vivemos hoje, é preciso que façamos mais do que os que estão em circunstâncias semelhantes. $O$ argumento de que não deveríamos fazer mais do que os outros somente seria plausível em uma situação na qual o total computado da ação de todos fosse o suficiente para atingir os resultados obrigatórios do ponto de vista moral: por exemplo, se todos em uma situação como a minha contribuem com $\mathrm{R} \$ 10$ para acabar com a fome; se o valor computado total dessas contribuições for o suficiente para satisfazer as necessitadas das pessoas com fome; então não tenho a obrigação de dar mais do que os que estão na mesma situação que a minha. Entretanto, esse argumento possui um contra-argumento prático relevante: nem todas as pessoas estão comprometidas em doar dinheiro para acabar com a fome, assim, é preciso doar mais para suprimir as necessidades fundamentais dos outros, que são mais importantes que meus desejos supérfluos. O limite do quanto é preciso doar é o necessário para evitar o tanto de sofrimento que existe, de fato, no mundo, desde que, com isso, o agente não esteja sacrificando nada de moralmente comparável, em outras palavras, desde que o nível do seu sofrimento não seja mais baixo do que o nível de sofrimento daqueles que se deve ajudar.
} 
substituindo "importância moral comparável" por "moralmente significativo". O princípio fraco da obrigação de ajudar não exigiria que as pessoas ajudassem até ficarem no mesmo nível daqueles que estão sendo ajudados; para Singer, o ponto de vista da ética impõe o princípio não qualificado como a regra de conduta ${ }^{8}$.

A tese da imparcialidade estrita no utilitarismo é, no entanto, objeto de críticas. Em textos posteriores, ele considerou essas críticas e reformulou as exigências impostas pelo utilitarismo. Em seguida, desenvolveremos as críticas mais importantes e as respostas e reformulações propostas por Singer.

\section{Super-rogatório $\mathrm{x}$ obrigatório}

A exigência do utilitarismo de preferência e a imparcialidade defendidos por Singer não são conciliáveis com a distinção tradicional entre ação imposta pelo "dever" e ação "superrogatória" - ou, pelo menos, essa distinção não pode ser posta da maneira como é tradicionalmente feita. A revisão proposta por Singer levaria a uma moralidade excessivamente exigente que não poderia ser colocada em prática pelas pessoas comuns em suas circunstâncias ordinárias, mas seria própria somente para santos ou heróis.

Segundo Urmson (1958, p. 198-199), seria possível esquematizar na filosofia moral, implícita ou explicitamente, três tipos de ações segundo o seu valor moral: a) as ações obrigatórias, aquelas em que se tem o dever ou obrigação de realização (dizer a verdade, cumprir as promessas etc.); b) as ações permitidas, que são indiferentes às considerações morais (ir ao teatro, praticar esportes etc.); c) as proibidas, ações que não se deve fazer (cometer um assassinato, mentir etc.). Mas esse esquema não é capaz de classificar todos os tipos de ações. Existem tipos de ações que não podem ser exigidas do ponto de vista da ética, pois estariam além do dever. O agente não possui o dever de realizá-las e deixar de fazer ações além do dever não é motivo de censura, mesmo que possuam "inestimável valor moral".

Santos e heróis são as pessoas que praticam uma ação além do que o dever exige em uma determinada circunstância. Santo é o indivíduo que realiza uma ação que vai além do seu

\footnotetext{
${ }^{8}$ Singer (2003j, p. 201. Grifo nosso), “[...] propus tanto uma versão forte como uma moderada do princípio que nos exige evitar as catástrofes. A primeira versão, que requer de nós que evitemos que ocorram danos a não ser que ao fazê-lo sacrificássemos algo de importância moral comparável parece exigir que atuemos até o ponto em que alcançamos a utilidade marginal. Devo dizer também que está é a versão que me parece correta. Propus também a mais moderada - que afirma que devemos evitar os danos a não ser que ao fazê-lo tenhamos que sacrificar algo moralmente significativo -, somente para mostrar que inclusive para atuar sob este princípio, certamente incontrovertido, seria necessária uma enorme mudança em nosso modo de vida. [...] não vejo boas razões para escolher a versão moderada do princípio e não a forte".
} 
dever pelo controle das suas inclinações e interesses. Herói é o indivíduo que realiza uma ação além do seu dever pelo controle do medo natural. Por exemplo, um médico cumpre o seu dever se permanecer com os seus pacientes em uma cidade devastada pela praga, mas se um médico, em um lugar distante, oferecer-se para acompanhar os poucos médicos que ficaram na cidade devastada seria uma ação além do seu dever. O soldado que obedece às suas ordens em situações nas quais a maioria desistiria cumpre o seu dever, mas o soldado que faz mais do que os seus superiores sequer pensariam em fazer realiza uma ação além do seu dever; por exemplo, o soldado que se lança sobre uma granada para salvar os outros membros do seu pelotão. Ações além do dever são aquelas praticadas pelas pessoas que humildemente se dedicam ao serviço dos outros, vida que nem sequer é considerada pela maioria das pessoas "honestas e boas" e que "muito menos se espera delas" (URMSON, 1958, p. 202).

Urmson salienta que os santos e heróis acreditam não estarem fazendo nada mais do que lhes é exigido. Subjetivamente, no momento da ação, o que foi feito apareceu-lhes como o seu dever moral, mas as ações consideradas heroicas ou santas não podem ser exigidas dos outros como uma imposição da ética.

\begin{abstract}
Para resumir esse tema, parece claro que não existe ação, por quixotesca, heroica ou santa que seja, que o agente pode não se considerar obrigado a realizar, tanto como pode sentir-se obrigado a dizer a verdade ou cumprir as suas promessas. Essas ações não se apresentam como opcionais ao agente quando as está pensando, mas, posto que só ele pode considerar tal ação como seu dever, e só desde de um ponto de vista especulativo, somente para si, não para os demais, e nem sequer para si de um modo objetivo, e posto que nada mais pode exigir que realize tal ato, como se lhe pode exigir que diga a verdade ou que cumpra as suas promessas, aqui surge a mais importante diferença entre essas ações e os deveres imóveis, que são deveres para todos e de todos os pontos de vista e cujo cumprimente é exigido (URMSON, 1958, p. 204).
\end{abstract}

Assim, as ações super-rogatórias são aquelas que ultrapassam os limites estritos do dever moral e, por essa razão, não se tem obrigação de realizá-las ${ }^{9}$. Quatro são as condições que identificam ações super-rogatórias: a) realizar a ação é opcional, pois não é exigida ou proibida por nenhum princípio moral obrigatório (apesar de subjetivamente as pessoas que realizam ações super-rogatórias possam acreditar que não fazem nada além do seu estrito dever); b) a ação vai além do que é prescrito pela moralidade ordinária; c) a ação é realizada intencionalmente com o objetivo de beneficiar os demais; d) a ação é "boa e digna" em si

\footnotetext{
${ }^{9}$ Urmson não utiliza, nesse artigo, o termo super-rogatório, mas seu texto é o ponto de partida da discussão contemporânea sobre a introdução dessa categoria em filosofia moral. A ideia sobre quais ações são superrogatórias aparece em seus exemplos.
} 
mesma, mas além da intenção do sujeito moral.

Apesar de muitas ações super-rogatórias serem realizados por "heróis" ou "santos", elas também podem ser realizadas por pessoas comuns. Por exemplo, quando uma pessoa presta serviços voluntários, faz uma doação generosa para alguma causa que considere meritória entre outras ações semelhantes.

Ajudar as pessoas que não possuem as condições mínimas de sobrevivência não é considerado, nesse esquema conceitual, como uma ação obrigatória, mas super-rogatória. Algumas pessoas doam uma pequena parte dos seus rendimentos porque é admirável e bondoso da sua parte, mas não veem nenhum problema em gastar com roupas da moda ou jantares caros. Os indivíduos que fazem doações recebem, muitas vezes, aprovação e são elogiados, mas os que nada fazem não são condenados, nem ao menos censurados. Deixar de realizar uma ação super-rogatória não leva à repreensão moral. São ações recomendáveis que possuem "inestimável valor" e devem ser motivo de grande admiração, mas as pessoas não estão moralmente obrigadas a realizá-las. A grande maioria nem mesmo está motivada a fazê-las em algum momento.

Os limites da moralidade comum não exigem que as pessoas alterem seriamente os seus "planos de vida" em favor de pessoas enfermas ou que estejam morrendo de fome. As exigências e custos pessoais que a ética de Singer impõe como obrigatórios estariam, de fato, além da obrigação imposta pela moralidade comum, seriam tão-só ideais recomendáveis.

O utilitarismo e a sua exigência de imparcialidade eliminariam a distinção entre superrogatório e obrigatório, o que transformaria a moralidade em um padrão excessivamente alto. Uma moralidade demasiado exigente pode ser devastadora, pois leva as pessoas a negligenciarem as suas responsabilidades.

O que o argumento sugere é que, se o dever moral impõe que as pessoas deveriam se abster de assassinar umas às outra, mas também deveriam entregar seus recursos para combater a fome no mundo, provavelmente não fariam nem uma coisa nem outra. Mas se a moralidade impõe a proibição ao assassinato, mas considera, ao mesmo tempo, como boa e louvável a ajuda ao combate à fome no mundo sem que seja moralmente errado deixar de fazê-la, pelo menos as pessoas não praticariam o assassinato. Assim, se um padrão moral mais realista e menos exigente fosse estabelecido, talvez as pessoas buscariam realizá-lo de fato. Se o dever moral é demasiado alto para ser seguido pelas pessoas comuns, elas não poderiam ser obrigadas a considerar essas exigências como sua obrigação. Para Beauchamp e Childress (2002, p. 286 e 288; ver também Urmson, 1958, p. 212): 
quanto mais amplamente generalizamos as obrigações de beneficência [superrogatórias], menos probabilidade há de que cumpramos nossas responsabilidades primárias, que muitos de nós já consideram difíceis de cumprir. [...] Quando os padrões da moralidade são altos demais para algumas pessoas, elas não podem participar do domínio da vida moral.

Na concepção de Singer, essa distinção entre "super-rogatório" e "obrigatório" não pode ser justificada conforme posta pela tradição. Para o filósofo australiano, consiste em uma obrigação moral ajudar os outros se não sacrificamos nada de moralmente significativo ou moralmente comparável. Deixar de comprar coisas supérfluas para ajudar a diminuir o sofrimento no mundo é uma obrigação do ponto de vista da ética. Da mesma forma, a doação a instituições de ajuda aos necessitados não é um ato de caridade, mas uma ação a qual se está obrigado. Diminuir o sofrimento não é um ato caridoso, de boa-vontade ou louvável, é uma obrigação, mesmo que leve a uma mudança radical no nosso modo de vida atual.

Singer acredita que existam alguns atos que podem ser classificados como superrogatórios, como o de promover a felicidade: "haveria muitos outros modos possíveis de estabelecer essa diferença (entre o dever e a caridade), por exemplo, pode-se decidir que é bom fazer aos demais tão felizes como seja possível, mas que não é mau deixar de fazê-lo" (SINGER, 2003j, p. 196). O utilitarismo proposto por Singer talvez possa ser considerado negativo. No utilitarismo negativo, o valor moral básico é eliminar ou, pelo menos, diminuir o sofrimento ao invés de se concentrar na maximização do prazer (POPPER, 1974, p. 256, nota 2; MULGAN, 2012, p. 157). Para Singer, a atual linha que separa o obrigatório do superrogatório deve ser retraçada ou eliminada.

\section{Ética da fantasia}

Uma crítica muito influente afirma que o utilitarismo é uma ética impraticável porque negligencia os deveres especiais que temos em relação aos indivíduos com os quais mantemos relações especiais e elimina qualquer importância que afetos parciais têm na vida das pessoas.

Mackie (2000, p. 149-150) argumenta que as paixões e os afetos parciais são parte inextirpável da natureza humana e são elementos da motivação para a ação das pessoas. As ações que procuram realizar esses afetos parciais não buscam a felicidade geral, tampouco são compatíveis com uma preocupação imparcial em relação àquelas pessoas com as quais não temos nenhuma relação especial. 
A imparcialidade negligencia o que Mackie (seguindo Broad) chamou de "altruísmo autorreferente": a preocupação que temos em relação aos outros, mas somente com aqueles com os quais mantemos algum tipo de relação especial: filhos, pais, amigos, companheiros de trabalho, em outras palavras, pessoas que nos são próximas de fato e não de modo metaforicamente ampliado. Não seria crível, nessa concepção, uma "devoção" ao bem-estar dos seres humanos em geral e muito menos de todos os seres sencientes.

De fato, as pessoas não vão pesar os interesses de todos os seres sencientes com os mesmos critérios que usam para pesar seus interesses próprios e objetivos específicos, tampouco vão pesar com o mesmo critério os interesses daqueles que lhe são próximos de fato. Essa preocupação não é o motivo real das suas escolhas e nem mesmo seria capaz de fazer com que as pessoas agissem como se fosse. Para Mackie, o utilitarismo e a sua exigência de imparcialidade estrita seriam uma "ética da fantasia".

Para outros autores, o problema principal em colocar os interesses dos outros à frente dos interesses dos indivíduos com os quais mantemos relações especiais não é a sua impraticabilidade ou as demasiadas exigências que fazem ao agente; a imparcialidade seria, na verdade, indesejável.

As pessoas possuem uma perspectiva autointerressada na qual as suas preocupações particulares e vínculos afetivos e sociais são importantes para si mesmas; essas relações tendem a ser enfraquecidas na medida em que a sua identificação com os outros diminui (JOLLIMORE, 2011 , 2.1 e $\S 3.2$ ).

A visão da moralidade ordinária que admite que um agente seja parcial em relação a si mesmo, aos seus próprios projetos e às preocupações tem um forte apelo intuitivo, pois, do ponto de vista subjetivo, eles têm um significado especial. Da mesma forma, a parcialidade em relação àquelas pessoas com as quais temos relações afetivas e especiais também é considerada ordinariamente como justificável em muitos casos.

Mas o princípio de igual consideração de interesses, tal como formulado por Singer, não concede aos afetos parciais e à perspectiva pessoal autointerressada um peso especial na deliberação moral; a perspectiva de qualquer outra pessoa importa tanto como a do agente e a do agente importa tanto como a de qualquer outra pessoa.

Para Thomas Nagel, a coexistência entre o ponto de vista autointeressado (no qual os afetos parciais ocupam o lugar central) e o ponto de vista desinteressado (no qual o agente precisa separar-se de sua posição particular e autointeressada para pensar em todas as pessoas sem colocar seu interesse próprio como o único significativo) tem como consequência uma 
divisão no $\mathrm{eu}^{10}$. Para que a teoria moral seja prática, ela não pode negligenciar esse aspecto da vida das pessoas.

Um dos aspectos centrais da filosofia moral na concepção de Singer é que ela deve ser aplicável satisfatoriamente às circunstâncias nas quais as pessoas de fato encontram-se. Se a teoria ética não é adequada às vicissitudes da vida cotidiana, não é uma boa teoria. Para Singer (CHV, p. 305), "se alguém propõe uma ética tão nobre que tentar viver à sua luz constitua um desastre para todos, então - independentemente de quem a propôs - não é uma ética nobre de todo, é uma ética estúpida que deve ser firmemente recusada”.

Se a parcialidade é um aspecto intrínseco e irrenunciável da vida das pessoas e se o utilitarismo de preferências exige que este aspecto seja suprimido, então essa teoria parece ser um "desastre para todos".

\section{Imparcialidade e parcialidade razoável}

É possível, em alguma medida, conciliar a imparcialidade com os afetos parciais? Singer, com o refinamento da sua teoria utilitarista, passa a considerar seriamente as críticas ao padrão excessivo do utilitarismo, que, na prática, pode tornar-se contraproducente e propõe argumentos para conciliar a parcialidade razoável com a sua concepção imparcial do ponto de vista da ética. Essa reformulação pode ser compreendida a partir de três diferentes argumentos: 1) um argumento ad hoc baseado na ideia do dízimo; 2) a existência de dois níveis do pensamento moral; 3) a justifica imparcial da parcialidade.

\section{O apelo à ideia de dízimo}

Para contornar o problema da exigência excessiva, Singer sugere um valor mínimo para ajudar: em torno de $10 \%$ da renda das pessoas que possuem rendimentos médios ou acima da média nas sociedades ricas ${ }^{11}$ (SINGER, EP, p. 258-259).

\footnotetext{
${ }^{10}$ Segundo Nagel (1996, p. 25), "está claro que para a maioria das pessoas, a coexistência da perspectiva impessoal produz uma divisão do eu. Cada pessoa, desde seu próprio ponto de vista interno ao mundo, com suas particulares preocupações e vínculos, é extremamente importante para si mesma, e está situada no centro de um conjunto de círculos concêntricos e representam uma rápida diminuição da identificação com os outros. Mas desde o ponto de vista impessoal que também pode ocupar, pode ser qualquer outro indivíduo. A vida de qualquer outro importa tanto como a sua, e a sua não mais do que a de qualquer outro."

${ }^{11}$ A formulação dessa regra ad hoc parece implicar que apenas as pessoas dos países ricos têm obrigação de ajudar, o que negligencia a imensa desigualdade no interior dos países pobres e a obrigação, quiçá maior, das pessoas com rendimentos acima da média desses países também ajudarem. Esse, provavelmente, pode ser apenas um descuido na expressão tendo em vista o público para o qual o livro Ética Prática foi inicialmente escrito, a saber, alunos
} 
A reformulação de Singer é arbitrária em relação ao limite da obrigação de ajudar, pois não tem relação com o princípio moral em que sua teoria se fundamenta. Parece que o valor escolhido tem função prática. Para Singer, $10 \%$ não é um valor alto para as pessoas que vivem nas sociedades ricas e não possuem despesas especiais. Um exemplo de despesas especiais poderia ser um tratamento médico. É um valor que também lembra o dízimo que muitos doam às igrejas. Nesse sentido, o valor baseia-se em uma prática que não parece nada absurda.

Contudo é um argumento ad hoc usado para minimizar as excessivas exigências que o utilitarismo faz às pessoas comuns em situações ordinárias. A distribuição desses 10\%, entretanto, ainda precisaria pesar as necessidades de cada afetado imparcialmente.

\section{Nível intuitivo do pensamento moral}

R. M. Hare propõe a existência de dois níveis no pensamento moral: o "crítico" e o “intuitivo”. O nível intuitivo é constituído por um conjunto de intuições morais amplamente compartilhadas, de regras prima facie, de máximas simples e gerais transmitidas ao longo dos séculos pela tradição por meio da educação. E muitas das intuições morais comuns estão particularmente relacionadas com a preocupação com os nossos próprios interesses e as obrigações em relação às pessoas próximas. Não se pode simplesmente descartar as relações especiais que mantemos e os afetos parciais constitutivos da natureza humana, porque elas são importantes e apropriadas para os seres humanos tal como somos ${ }^{12}$; por serem importantes para os seres humanos, eliminá-los não levaria à maximização do bem-estar.

Para Singer, portanto, assumir uma perspectiva imparcial resultará nas melhores consequências se aceitarmos e promovermos adequadamente os afetos parciais e as relações especiais que mantemos. Para tanto, é preciso reforçar métodos intuitivos de decisão moral que considerem adequadamente tais afetos.

Mesmo que os afetos parciais e as relações especiais sejam uma importante fonte de motivação, promover um cenário ético no qual há cuidado "em excesso" com os membros da

\footnotetext{
dos cursos introdutórios de ética das universidades dos países desenvolvidos de língua inglesa.

12 Para Singer (2003k, p. 227), "nossos sentimentos por nossas próprias esposas, filhos, amantes ou amigos íntimos estão profundamente enraizados em nossa própria natureza. Os homens evoluíram como mamíferos que vivem em grupos sociais pequenos e relativamente estáveis. Isso significa que nos interessa proteger nossos parentes e construir relações recíprocas de larga duração com outros que não estão ligados conosco. Se bem que não podemos derivar conclusões éticas diretamente do fato de que esses afetos parciais nos sejam naturais, não deve surpreender que qualquer conjunto de regras ou princípios que sejam eficazes para a vida cotidiana tenha que refletir (e ser construído sobre a base de) esses aspectos de nossa natureza. Fazer de outro modo seria ir contra a realidade das coisas."
} 
família ou com o próprio grupo pode levar a consequências desastrosas como o ufanismo ${ }^{13}$.

Não existe, entretanto, uma separação intransponível entre os dois níveis. No nível crítico, avalia-se se as intuições morais comuns não estariam levando ao cuidado "excessivo" que ultrapassasse qualquer limite razoável a ser aceito de uma perspectiva imparcial. Se as intuições morais comuns não passam pela crítica, devem ser, em algum momento, descartadas como guias de conduta mesmo no nível intuitivo.

\section{Justificativa imparcial da parcialidade}

Singer admite um "pequeno grau" segundo o qual o agente pode dar prioridade às preferências e interesses de sua família ou comunidade somente se essa prioridade for justificada imparcialmente. Se a família e a comunidade são importantes para aumentar o bemestar, então existe uma razão objetiva e imparcial para dar prioridade aos interesses do agente e aos interesses dos indivíduos com os quais mantem relacionamentos especiais até ao ponto em que se possa garantir a maximização do bem-estar.

O elemento de verdade no ponto de vista de que primeiro devemos cuidar de nós mesmo está na vantagem de um sistema identificável de responsabilidade. Quando as famílias e as comunidades locais cuidam dos seus próprios membros mais pobres, os laços de afeição e das relações pessoais obtêm resultados que, de outra forma, precisariam de uma enorme e impessoal burocracia. [...] Permitir que alguém das próprias relações de parentesco mergulhasse em pobreza seria sacrificar algo de importância comparável; e, antes que chegasse a esse ponto, o colapso do sistema de responsabilidades para com a família e a comunidade seria um fator a fazer com que a balança pendesse para o lado de um pequeno grau de preferência pela família e pela comunidade. Contudo, esse pequeno grau de preferência é decisivamente superada pelas discrepâncias que se verificam nas esferas da riqueza e da propriedade (SINGER, EP, p. 244-245).

A justificativa utilitarista de Singer não significa que os pais devem amar seus filhos, porque esse é o modo de maximizar o bem-estar; se o amor dos pais pelos filhos é uma fonte de bem-estar importante, sendo quase impossível eliminá-la ou substituí-la, seguir essas inclinações passa a ser parte importante das obrigações morais de uma pessoa. Assim, devemse cumprir as obrigações com os filhos não porque isso é o que maximiza o bem-estar, mas porque o amor paternal é fonte de bem-estar (SINGER, 2003k, p. 222).

\footnotetext{
13 Talvez um exemplo do "cuidado excessivo" com a própria família seja o nepotismo, tão presente no serviço público brasileiro (SINGER, CHV, p. 189).
} 
Se a experiência mostra que o bem-estar geral é alcançado de forma mais satisfatória se os homens agirem por motivos distintos da pura "filantropia universal" e se esses outros motivos forem justificados razoavelmente, eles serão recomendados pelo princípio utilitarista (SIDGWICK, 1907, p. 413). Isto é, existem razões neutras a respeito do agente que justificam ações baseadas em razões relativas a respeito do agente. Singer esclarece que:

[...] podemos dar, amiúde, razões que são neutras a respeito do agente para elogiar aqueles que atuam se baseando em razões relativas ao agente. Em última instância, o ponto de vista neutro a respeito do agente é que determina se uma ação é correta; mas é um erro centra-se sempre na correção das ações individuais mais que nos hábitos ou maneiras intuitivas de pensar do que cabe esperar que, ao longo de uma vida, produzam o maior bem possível. Daqui que é preciso uma teoria da virtude que critique a excessiva atenção à correção das ações e dirija nossa atenção para a questão do tipo de caráter que uma boa pessoa tem. Não obstante segue vigente uma teoria que é imparcial no sentido definido no primeiro parágrafo deste artigo [impessoal, objetiva, universal] o consequencialismo de dois níveis. (SINGER, 2003k, p. 228).

Razões neutras a respeito do agente não compreendem nenhuma referência essencial à pessoa que as tem: a sua avaliação é objetiva e independente dos interesses próprios do agente. Razões relativas a respeito do agente fazem referências essenciais à pessoa que as tem; tais razões podem ser classificadas em três categorias: a) as razões de autonomia que surgem dos interesses do agente e o induz aos seus próprios objetivos. Nesse sentido, as razões relativas a respeito do agente limitam a obrigatoriedade de se realizar ações baseadas em preceitos estritamente imparciais que prejudicassem os objetivos finais dos indivíduos; b) as razões deontológicas que surgem da obrigação de não infligir danos ao outro em sua relação com o agente. Assim, ações imparciais que causam danos a uma pessoa não seriam justificadas; c) as razões de obrigação que surgem das obrigações que temos com as pessoas com as quais mantemos relações afetivas ${ }^{14}$.

O utilitarismo estritamente imparcial é caracterizado como uma teoria neutra a respeito do agente na medida em que os interesses deste e de todos os pacientes afetados pela sua ação devam ser avaliados independente do sujeito que possui o interesse. Os interesses são comparados considerando apenas a sua "força" ou "peso". Em outras palavras, é possível estabelecer critérios objetivos, quiçá quantitativamente elaborados, para avaliar o ato do agente

\footnotetext{
14 “Todas essas razões são compatíveis com o sentido comum, já que cada um deve viver a sua própria vida (autônoma), dar especial consideração a quem lhe é próximo (obrigação) e tratar decentemente as pessoas com quem se relaciona (deontologia). Não obstante, pode-se produzir conflitos internos ao se apresentar casos em que atuar de acordo com uma delas suponha o sacrifício da outra." (ARRIETA, 2000, p. 187).
} 
sem referência ao mesmo. A decisão moral de qual a ação maximiza as melhores consequências é tomada baseando-se estritamente nesse "cálculo".

Ao assumir que pessoas devem agir baseadas em razões relativas ao agente e que, em certos casos, possuem a obrigação de agir assim, Singer justifica esse ponto a partir de razões neutras a respeito do agente. $\mathrm{O}$ utilitarismo, em seu nível crítico, mantém-se em bases estritamente imparciais e passa a incorporar o altruísmo autorreferente como uma parte da teoria.

Em resumo, a filosofia moral contemporânea busca resolver a discordância entre o ponto de vista imparcial e o parcial ao abordar problemas práticos. Singer assume um ponto de vista estritamente imparcial na ética: cada preferência conta como uma independente de quem as tem. Entretanto, em razão das inúmeras críticas a sua posição, ele passou a assumir que existem razões utilitaristas estritamente imparciais que justificam a parcialidade em determinadas circunstâncias.

\section{Referências}

ARRIETA, T. Sobre el agente moral. In.: GIUSTI, M. La filosofia del siglo XX. Actas del VII Congresso Nacional de Filosofía. Pontifícia Universidad Católica del Peru: Fondo Editorial, 2000. 185-200.

BEAUCHAMP, T. L.; CHILDRESS, J. F. Princípios de Ética Biomédica. 2 ed. Tradução de Luciana Pudenzi. Loyola, 2002.

BLUM, L. Iris Murdoch and the Domain of the Moral. Philosophical Studies, 50, 1986, p. 343-367.

COTTINGHAM, J. Ethics and Impartiality. Philosophical Studies, 43, 1983, p. 83-99.

GODWIN, W. Enquiry concerning political justice and its influence on moral and happiness. Third edition corrected in two volumes. London: Printed for G. G. and J. Robinson, Paternoster-Row, 1798. V.1.

GRUEN, L. Must Utilitarians be Impartial? In: JAMIESON, D. (ed.). Singer and his critics philosophers and their critics. Oxford-Malden: Brackwell, 1999. p. 129-149.

HARE, R. M. Freedom and Reason. Oxford: Oxford University Press, 1965.

JOLLIMORE, T. Impartiality. ZALTA, E. N. (ed). The Stanford Encyclopedia of Philosophy. Spring, 2014. Disponível em: http://plato.stanford.edu/archives/spr2014/entries/impartiality Acessado em 21/03/2014.

MACKIE, J. L. Ética: la invención de lo bueno y lo malo. Traducción de Tomás Fernandez Aúz. Barcelona: Gedisa, 2000. 
MULGAN, T. Utilitarismo. Tradução de Fábio Creder. Petrópolis: Vozes, 2012.

NAGEL, T. Igualdad y parcialidad. Bases éticas de la teoría política. Traducción de José F. A. Álvarez. Barcelona-Buenos Aires-México: Paidos, 1996.

PLATO. Euthyphro. In.: PLATO. Complete Work. Edited, with Introduction and Notes, by John M. Cooper. Associate Editor D. S. Hutchinson. Indianapolis-Cambridge: Hackett Publishing Company, 1997.

POPPER, K. R. A sociedade aberta e seus inimigos. Tomo I: O fascínio de Platão. Tradução de Milton Amado. Belo Horizonte: Itatiaia - São Pulo: EdUSP, 1974.

SIDGWICK, H. The Methods of Ethics. Seventh edition. London-NewYork: MacMillam, 1907.

SINGER, P. A response. In: JAMIESON, D. (ed.). Singer and his critics philosophers and their critics. Oxford-Malden: Brackwell, 1999. p. 269-335.

Como havemos de viver: a ética numa época de individualismo. Trad. Fátima St. Aubyn. Lisboa: Dinalivro, 2006a. (CHV) Ética Prática. $3^{\circ}$ Ed. Trad. J. L. Camargo. São Paulo: Martins Fontes, 2006b. (EP) . Hambre, opulencia y moralidad. In: SINGER, P. Desacralizar la Vida Humana. Introducción e edición de Helga Kuhse. Madrid: Cátedra, 2003j. p. 189-203.

CANNOLD, L; KUHSE, H. William Godwin y la defensa de la ética imparcialista. In: SINGER, P. Desacralizar la Vida Humana. Introducción e edición de Helga Kuhse. Madrid: Cátedra, 2003k. p. 204-229.

MILL, J. S. Utilitarismo. Tradução, introdução e notas de Pedro Galvão. Porto (Portugal): Porto Editores, 2005.

URMSOM, J. Saints and Heros. In.: WOOD, A. Essays in Moral Philosophy. Seattle: University of Washington Press, 1958. p. 196-216. 